\title{
Early Event of Sexual Induction in Volvox: Chemical Modification of the Extracellular Matrix
}

\author{
StePhan WenzL ${ }^{1}$ and MANFred Sumper \\ Institut für Biochemie, Genetik und Mikrobiologie, Universität Regensbnırg, 8400 Regensburg, West Germany
}

Received June 18, 1985; accepted in revised form December 5, 1985

\begin{abstract}
The sexual pheromone of Volvox carteri elicits drastic changes in the synthesis of extracellular sulfated glycoproteins. Synthesis of at least two sulfated glycoproteins is turned on. Induction of this synthetic capacity is as sensitive to the pheromone $\left(\sim 10^{-16} M\right)$ as the overall process of sexual induction. The earliest response, detectable a few minutes after the application of the pheromone, is the synthesis of a tyrosine sulfate-containing glycoprotein (SG 70). SG 70 is a short-lived molecule (half-life $\sim 20 \mathrm{~min}$ ) and serves as a precursor for an insoluble extracellular matrix structure. The pheromone-induced sulfated glycoproteins described are exclusively synthesized by somatic cells, rather than by reproductive cells, the ultimate recipients of the pheromone's message. Contrary to earlier reports in the literature, it is demonstrated that isolated reproductive cells remain responsive to the sexual pheromone and develop to sexual spheroids. In the light of this finding together with the site of their synthesis the role of these pheromone-induced glycoproteins is discussed. (1986 Academic Press, Inc.
\end{abstract}

\section{INTRODUCTION}

The elegantly simple manner in which developmental phenomena are presented by the multicellular green flagellate Volvox carteri makes this organism well suited for the study of cellular differentiation. The organism undergoes embryogenesis and somatic cells become separated from germ line cells as clearly as in a diagram. Reproductive cells (gonidia) are set aside at distinct cleavage stages by unequal divisions of certain cells (Powers, 1908; Janet, 1923; Kochert, 1968; Starr, 1969, 1971; Green and Kirk, 1981, 1982).

Figure 1 shows a highly schematic cross section of a Volvox carteri spheroid (for a more detailed analysis, see Kochert and Olson (1970)). 2000-4000 somatic cells are embedded as a monolayer in a sheath of extracellular matrix material (ECM), which forms a hollow sphere. The ECM sheath shows considerable structural organization in that it exhibits clearly visible boundaries toward the interior (I) of the spheroid as well as honeycomb-like structures around each somatic cell. Sixteen gonidia are positioned in a highly regular pattern in the posterior two-thirds of the spheroid (Starr, 1970; Sumper, 1979; Gilles and Jaenicke, 1982). The cell-free inner space (I) of the spheroid is filled with highly viscous polysaccharide-rich material. By exerting mild mechanical stress, a Volvox spheroid is reproducibly dissociated into single reproductive cells and somatic cell sheets containing all the ECM material, while the polysaccha-

\footnotetext{
${ }^{1}$ To whom correspondence should be addressed.
}

ride-rich material of the I compartment is released into the medium.

A new individual is formed from each reproductive cell in a series of cleavages. In the developing asexual embryo, differentiation into somatic and reproductive cells is seen at the division from 32 to 64 cells. At this stage, 16 out of the 32 cells undergo unequal cleavage, forming a small somatic and a large reproductive initial. Whereas cell division soon ceases in the reproductive initials, the remaining cells continue to divide and finally differentiate into somatic cells.

This developmental program of Volvox can be changed at will to that of sexual reproduction by addition of a sexual inducer to the growth medium (Starr, 1969; Starr and Jaenicke, 1974). In the female strain, the action of this pheromone is to delay the differentiating cell cleavage until the division from 64 to 128 cells. At this stage, again about half of the embryonic cells undergo unequal cleavage and form 32 reproductive initials. These reproductive initials differentiate to egg cells. In the male strain, the differentiating cleavage is delayed even longer under the influence of the sexual inducer. Differentiation into sperm-producing cells (androgonidia) and somatic cells occurs at the final division, which in male embryos occurs at the 128- or 256-cell stage.

The Volvox carteri pheromone, the "sex inducer" (Starr and Jaenicke, 1974; Gilles et al., 1981) is a 30,000$\mathrm{Da}$ glycoprotein, which is synthesized and secreted by sperm cells. Extremely low concentration of this pheromone $\left(\sim 10^{-16} M\right)$ fully trigger sexual development in 


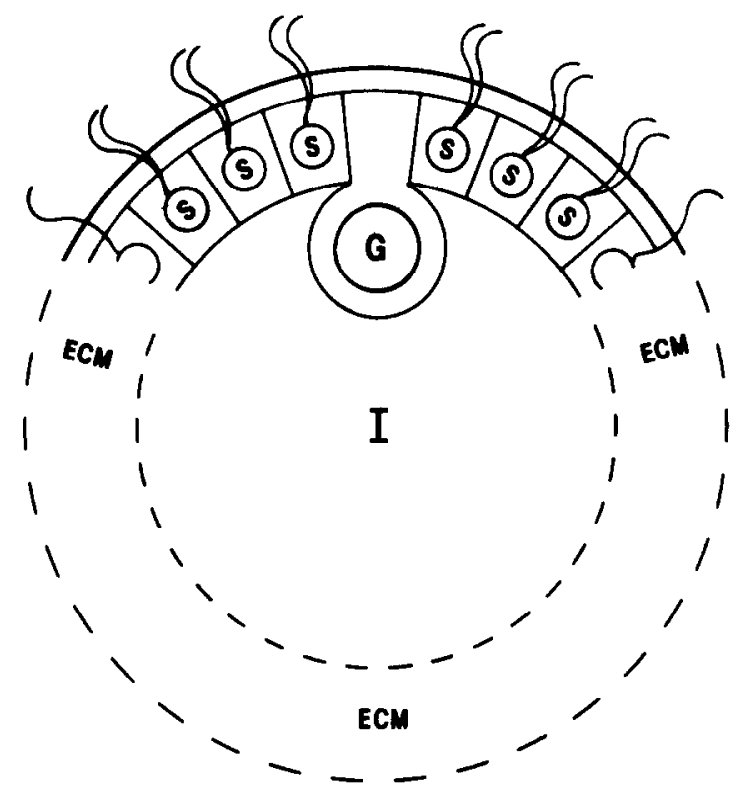

FIG. 1. Schematic drawing of a cross section through a Volvox spheroid. S, Somatic cell; G, gonidium; ECM, extracellular matrix; I, cellfree interior of the spheroid.

both the male and female strains. This fact calls for a potent signal amplification mechanism.

The biochemical mechanism of the pheromone's action is almost completely unknown. The ultimate target of inducer action obviously is the reproductive cell (gonidium) of the asexual spheroid, which responds by cleaving to produce a sexual rather than an asexual offspring. However, the first biochemical response detected so far is a structural alteration within the extracellular matrix. Only 10 min after application of the pheromone, synthesis of the sulfated extracellular glycoprotein SSG 185 is switched to produce a slightly different SSG 185 variant (Wenzl et al., 1984). 20 min later, synthesis of a completely new sulfated extracellular glycoprotein (F-SG) becomes detectable (Wenzl and Sumper, 1982). In addition, as reported by others phosphorylation of an extracellular glycoprotein (pp. 290) is transiently reduced (Gilles et al., 1983).

In this paper, we describe in detail a new pheromoneinduced glycoprotein which contains tyrosine-linked sulfate. In addition, we present experimental results limiting the possible functions of the pheromone-induced modification of the extracellular matrix.

\section{MATERIALS AND METHODS}

Culture conditions. Volvox carterif. nagariensis, strain HK 10 (female), was obtained from the Culture Collection of Algae at the University of Texas at Austin (R. C. Starr). Synchronous cultures were grown in Volvox medium (Provasoli and Pintner, 1959 ) at $28^{\circ} \mathrm{C}$ in an 8hr dark/16-hr light (8000-10,000 lux) cycle (Starr and Jaenicke, 1974).

Pulse-chase labeling experiments. Pulse-labeling with ${ }^{35} \mathrm{SO}_{4}^{2}$ was performed as described by Wenzl and Sumper (1981). Briefly, about 750 Volvox colonies at the appropriate developmental stage were suspended in $0.5-\mathrm{ml}$ sulfate-free Volvox medium. After addition of $20 \mu \mathrm{Ci}$ $\left(7.40 \times 10^{5} \mathrm{~Bq}\right)$ of radioactive sulfate (specific activity 35 $\mathrm{mCi} / \mu \mathrm{mol})$, the suspension was magnetically stirred under illumination $(15,000 \mathrm{lux})$ at $27^{\circ} \mathrm{C}$ for times indicated. After the pulse period, the labeled colonies were washed with sulfate-containing Volvox medium and resuspended in the same medium for the subsequent chase period. The chase, which lasted for $90 \mathrm{~min}$, was performed under conditions otherwise identical to those used for the pulse.

SDS extraction of intact Volvox spheroids. Aliquots of pulse- (or pulse-chase-) labeled spheroids were diluted with 2 vol of SDS-sample buffer (Laemmli, 1970) and heated for $10 \mathrm{~min}$ at $95^{\circ} \mathrm{C}$. After centrifugation, $50-\mu 1$ aliquots (which corresponds to radioactivity incorporated by 25 Volvox spheroids) of the supernatant were applied to a $6 \%$ SDS-polyacrylamide gel. SDS-polyacrylamide gel electrophoresis was performed as described by Laemmli (1970). Fluorography was performed according to Bonner and Laskey (1974); exposure times were $6-12 \mathrm{hr}$ at $-70^{\circ} \mathrm{C}$.

Preparation of Volvox "ghosts". For hydrogen fluoride treatment, pulse- (or pulse-chase-) labeled spheroids were mixed with two volumes of a solution containing $3 \%$ SDS and $1 \mathrm{M} \mathrm{NaCl}$, and then heated for $10 \mathrm{~min}$ at $95^{\circ} \mathrm{C}$. After washing with $\mathrm{H}_{2} \mathrm{O}$, the Volvox ghosts containing insoluble extracellular matrix material were lyophilized.

Isolation of ${ }^{35}$ S-labeled SG 70. About 750 Volvox spheroids were suspended in $0.5-\mathrm{ml}$ sulfate-free Volvox medium and $30 \mathrm{~min}$ after the addition of pheromone ( $1 \mathrm{pM})$ pulse labeled for $30 \mathrm{~min}$ as described above. $50 \mu \mathrm{l}$ of 5 $M \mathrm{NaCl}$ was added to the Volvox suspension. After 20 min Volvox spheroids were removed by centrifugation and the supernatant (containing ${ }^{35}$ S-labeled SG 70) applied to a SDS-polyacrylamide gel (6\%). SG 70 was localized by autoradiography and subsequently eluted from the homogenized gel with water. The eluate was dialyzed against $1 \mathrm{mM} \mathrm{NaCl}$.

Hydrogen fluoride treatment. Anhydrous hydrogen fluoride (Merck) was condensed into a polyethylene tube cooled in liquid nitrogen (Mort and Lamport, 1977; Wieland et al, 1983). Immediately after the acid melted, 100$\mu \mathrm{l}$ portions were pipetted onto samples of about 750 dried Volvox ghosts in plastic microreaction vials. The vials were closed and incubated for $90 \mathrm{~min}$ at $0^{\circ} \mathrm{C}$. The reac- 
tions were stopped by blowing the hydrogen fluoride into a fume hood in a gentle stream of nitrogen. The dried samples were dissolved in SDS-sample buffer, and applied to an SDS-polyacrylamide gel.

Cyanogen bromide (CNBr) cleavage. Dried samples of SG 70, and of HF treated Volvox ghosts were dissolved in $100 \mu \mathrm{l} \mathrm{CNBr}$ solution ( $1 \mathrm{mg} / \mathrm{ml}$ in $70 \%$ formic acid) and kept at $20^{\circ} \mathrm{C}$ for $24 \mathrm{hr}$. The reaction was stopped by lyophilization, and the products were analyzed on a $15 \%$ SDS-polyacrylamide gel.

Analytical determinations. For determination of sulfur-containing amino acids, dried ${ }^{35} \mathrm{~S}$-labeled SG 70 was treated with formic acid $/ \mathrm{H}_{2} \mathrm{O}_{2}$ (Hirs, 1967a) for $4 \mathrm{hr}$ at $0^{\circ} \mathrm{C}$ in the presence of unlabeled cysteine and methionine. The reaction was stopped by lyophilization. Amino acid analyses were performed after hydrolysis of samples in constant boiling $\mathrm{HCl}$ at $105^{\circ} \mathrm{C}$ for $24 \mathrm{hr}$, followed by dansylation (Seiler 1970). Dansylated amino acids were chromatographed on polyethylene imine thin layer sheets (Schleicher \& Schüll, Dassel, Federal Republic of Germany) with $0.3 \mathrm{M}\left(\mathrm{NH}_{4}\right) \mathrm{HCO}_{3}$ as solvent. Spots were detected by autoradiography and by observation under UV light.

Carboxymethylation of SG 70 was performed according to White (1967) and Hirs (1967b). Briefly, ${ }^{35}$ S-labeled SG 70 was reduced with a large excess of mercaptoethanol at pH 8.5 in the presence of urea $(8 M)$ as denaturing agent for $4 \mathrm{hr}$ at $25^{\circ} \mathrm{C}$. After reduction, $\mathrm{SH}$ groups were blocked with iodoacetic acid $(250 \mathrm{mM})$ at $\mathrm{pH} 8.5$ for 30 min at $25^{\circ} \mathrm{C}$. The solution was acidified to $\mathrm{pH} 4.0$ and applied to gel filtration over a column of Sephadex G25 equilibrated with $0.1 M$ acetic acid. The effluent was collected in fractions. The protein containing fractions were pooled and lyophilized. Hydrolysis in the presence of unlabeled carboxymethylcysteine was performed as described above. Carboxymethylcysteine was identified by comparison with the internal standard after highvoltage electrophoresis at $2000 \mathrm{~V}$ for $80 \mathrm{~min}$ in acetic acid $/$ water $/$ pyridine $=60 / 934 / 6(\mathrm{pH} 3.5)$ on cellulose thin layer chromatography plates $20 \times 40 \mathrm{~cm}$ (Polygram, Macherey-Nagel).

To determine tyrosine- $O$-sulfate, dried ${ }^{35} \mathrm{~S}$-labeled SG 70 was dissolved in $0.2 \mathrm{MBa}(\mathrm{OH})_{2}$, and hydrolyzed at $110^{\circ} \mathrm{C}$ for $24 \mathrm{hr}$ (Bettelheim, 1954) in the presence of unlabeled tyrosine- $O$-sulfate, synthesized as described (Tallan et al, 1955). The hydrolysate was passed through a column of Dowex AG $50-\times 8\left(\mathrm{H}^{+}\right.$form) $(0.5 \mathrm{ml}$ bed volume) to remove $\mathrm{Ba}^{2+}$ ions and underivatized amino acids (Bettelheim, 1954). After neutralization, the eluate was lyophilized and dissolved in a small volume of water. After dansylation of an aliquot both samples were applied to high-voltage thin layer electrophoresis (conditions see above). Tyrosine- $O$-sulfate and dansyltyrosine-
$O$-sulfate were visualized by the ninhydrin reaction and UV detection, respectively.

Apparent molecular weights on SDS gels were estimated using protein standards purchased from Boehringer, Mannheim.

Isolation of gonidia. Immediately after release from mother colonies, young spheroids were disrupted by forcing them through a $0.4-\mathrm{mm}$ hypodermic needle. The suspension was filtered through a $40-\mu \mathrm{m}$-mesh nylon cloth through which only free gonidia and single somatic cells pass. Gonidia were separated from somatic cells on a 10- $\mu \mathrm{m}$-mesh nylon cloth, which retains only gonidia. Subsequently, the gonidial suspension was allowed to settle several times and the supernatant, which might contain somatic cell sheets, was discarded each time. Single gonidia were then identified under a stereomicroscope, and picked up using a drawn plastic pipette. Somatic cell sheets, collected on a $40-\mu \mathrm{m}$-mesh nylon cloth were inspected under a stereomicroscope and only gonidia-free cell sheets were picked out.

Preparation of solid media. $6.5 \mathrm{~g}$ starch (Serva, Heidelberg) were dissolved in $100 \mathrm{ml}$ Volvox growth medium by boiling. After the medium was cooled to $45^{\circ} \mathrm{C}$, the sexual pheromone was added at the appropriate dilution, and the solution immediately poured into petri dishes. Solidification occurred in a refrigerator at $4^{\circ} \mathrm{C}$.

Preparation of the sexual inducer. Sexual inducer was prepared according to Starr and Jaenicke (1974). Further purification was achieved as previously described (Wenzl et al., 1984).

\section{RESULTS}

\section{Pheromone-Induced Modifications of the \\ Extracellular Matrix}

In our previous studies, the pheromone-induced changes in sulfated glycoprotein synthesis have been analyzed by SDS gel electrophoresis of partially purified Volvox extracts ("crude membrane fraction," containing all sedimentable components of an ultrasonic Volvox lysate). To detect all pheromone-induced effects on the synthesis of sulfated macromolecules we repeated our pulse labeling studies with ${ }^{35} \mathrm{SO}_{4}^{2-}$, and extracted the labeled Volvox spheroids by boiling in $3 \%$ SDS. 10-min pulses were performed over a period of $3 \mathrm{hr}$ following the application of the pheromone. For this experiment, a synchronous Volvox population at the developmental stage of optimal sensitivity towards the pheromone (8 $\mathrm{hr}$ before the onset of gonidial cleavages) was used. The results of this experiment reveal an even more drastic response to the pheromone (Fig. 2B) than that observed earlier. Besides the induced synthesis of F-SG another synthetic activity is predominant: About $10 \mathrm{~min}$ after the application of the pheromone, synthesis of an as yet 


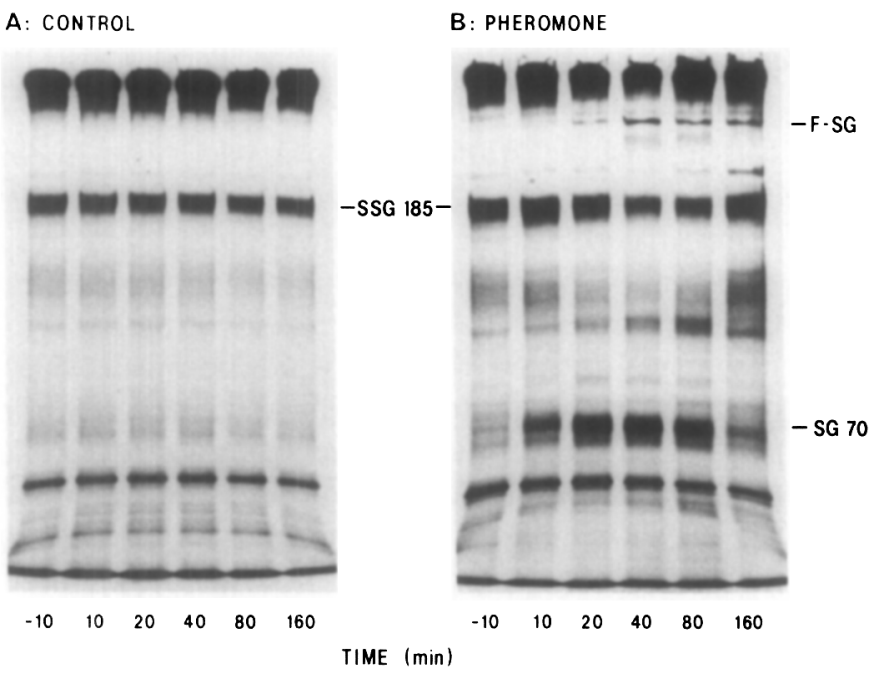

F'IG. 2. Pheromone-induced synthesis of sulfated glycoproteins. Fluorograms of SDS polyacrylamide gels $(6 \%)$ loaded with extracts from Volvox spheroids pulse labeled with ${ }^{36} \mathrm{SO}_{4}^{2-}$ for $10 \mathrm{~min}$. A synchronously growing Volvox population was divided $8 \mathrm{hr}$ before the onset of embryonic cleavages. One-half served as control (A), the other half (B) was treated with pheromone $\left(10^{6}\right.$-fold dilution of the pheromone stock which was fully active in the biological assay up to a $10^{8}$ fold dilution, i.e., the applied pheromone concentration was about 0.01 $\mathrm{p} M$ ). After application of pheromone (zero time), aliquots of the Volvox populations were pulse labeled at the times indicated (Materials and Methods). The labeled spheroids were boiled for $10 \mathrm{~min}$ in SDS sample buffer and aliquots of the extract (corresponding to 25 spheroids) were submitted to electrophoresis. Labeled material was visualized by fluorography $(10 \mathrm{hr})$.

unobserved ${ }^{35} \mathrm{~S}$-labeled component, with an apparent molecular weight of 70,000 , becomes detectable in the SDS gel pattern. Subsequently, the rate of synthesis of this material (denoted in the following as sulfated glycoprotein SG 70) increases and reaches a maximum about 30 min later. After $160 \mathrm{~min}$, synthesis of SG 70 is no longer detectable. Thus, this response to the pheromone is made over a period as short as only $150 \mathrm{~min}$ in the 48-hr life cycle of Volvox. The control experiment (Fig. 2A), i.e., pulse labeling of Volvox spheroids at exactly the same times but in the absence of pheromone, shows no changes at all in the labeling patterns.

\section{Dose Dependency of Pheromone-Induced SG ro Synthesis}

As noted earlier, the Volvox induction system exhibits exquisite sensitivity. The inducer is active at about $10^{-16}$ $M$ (Starr, 1970; Gilles et al., 1984). If SG 70 synthesis is indeed one of the events causing the reproductive cell to commence sexual development, then synthesis of this sulfated glycoprotein should show the same exquisite sensitivity of response to the pheromone as the overall process of sexual induction. To check this point, a serial dilution experiment was performed. A $10^{8}$-fold dilution of our pheromone stock solution was fully active in the biological assay (i.e., $100 \%$ of a Volvox population was triggered to sexual development). At $10^{9}$-fold dilution, the inducing capacity dropped to less than $80 \%$ and further dilutions remained inactive (Fig. 3A). Therefore, we repeated the ${ }^{35} \mathrm{SO}_{4}^{2-}$ pulse-labeling experiment described in Fig. 2 in the presence of pheromone concen-

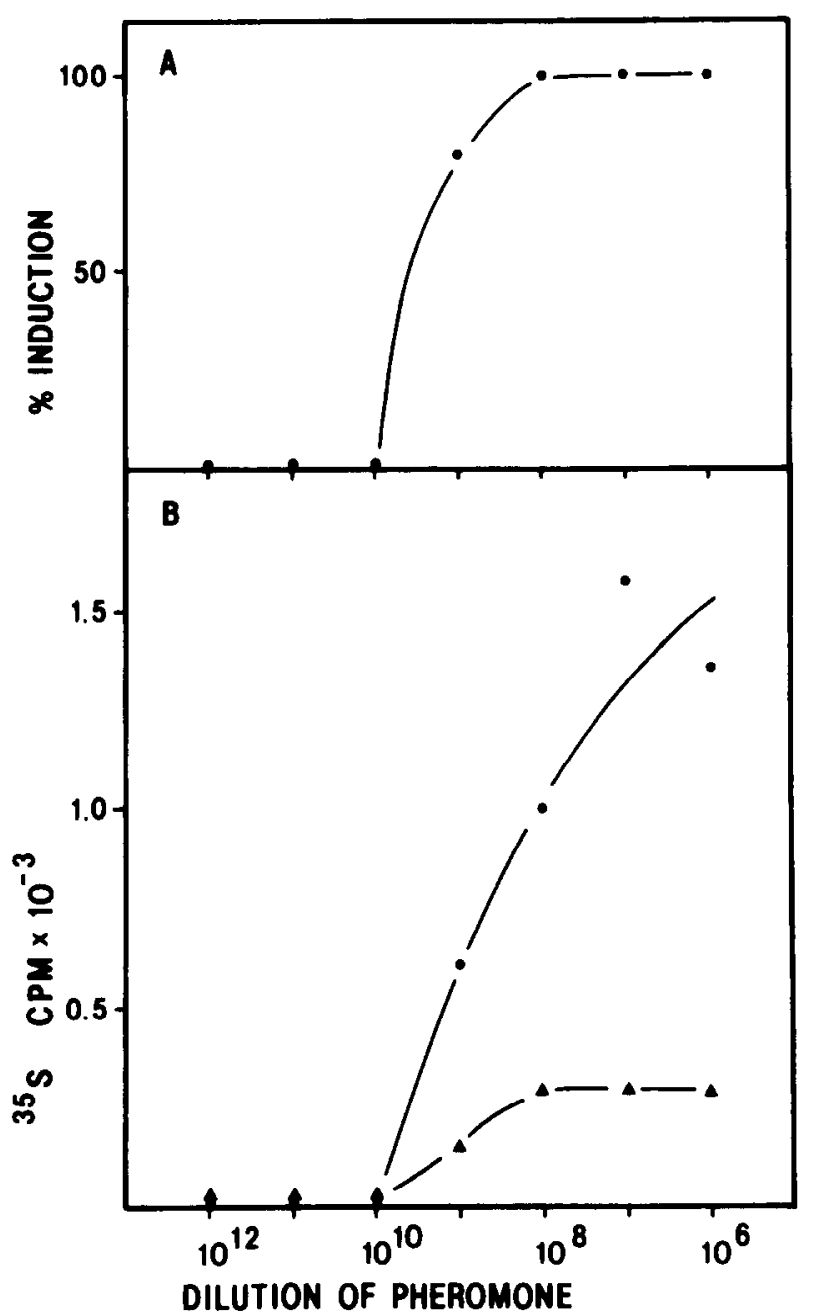

FIG. 3. Pheromone dose dependency of sexual induction (A) and of sulfated glycoprotein synthesis (B). Synchronously growing Volvox spheroids $8 \mathrm{hr}$ before onset of embryogenesis were concentrated to 50 spheroids per $\mathrm{ml} .2-\mathrm{ml}$ aliquots of the speroid suspension were treated with pheromone at the dilution indicated. $30 \mathrm{~min}$ later, $1-\mathrm{ml}$ aliquots were pulse labeled with carrier-free ${ }^{35} \mathrm{SO}_{4}^{2-}(100 \mu \mathrm{Ci})$ for $30 \mathrm{~min}$. Spheroids were extracted with SDS (Materials and Methods) and the extracts (corresponding to 25 spheroids) applied to SDS-polyacrylamide gels (6\%). After fluorography SG 70 and F-SG bands were cut out and the radioactivity incorporated was measured by liquid scintillation counting (B). $\bullet$, SG 70; $\Delta$, F-SG. The remaining spheroid suspensions (1 ml each) were further incubated and the percentage of sexual induction was determined microscopically after the end of embryogenesis (A). 
trations covering the range around the threshold value. The quantitative evaluation of the corresponding labeling patterns with respect to SG 70 synthesis (as well as F-SG synthesis) is shown in Fig. 3B. The sensitivity to the pheromone of SG 70 (and F-SG) synthesis is similar to that of sexual induction. This result supports involvement of these macromolecules in the process of sexual induction.

\section{SG 70 is a Short-lived Precursor Molecule}

SSG 185 was shown to be a short-lived glycoprotein which aggregates to form an insoluble extracellular matrix structure (Wenzl et al., 1984). An analogous experimental approach revealed a similar function for SG 70 . (1) A pulse-chase-labeling experiment demonstrates that SG 70 is a short-lived protein (Fig. 4, lanes 1 and 2). Its measured half-life is about $20 \mathrm{~min}$. (2) At the end of the chase period (after complete disappearance of SG 70), the labeled Volvox spheroids were boiled for $10 \mathrm{~min}$ in $3 \%$ SDS containing $1 \mathrm{M} \mathrm{NaCl}$. This rigorous procedure
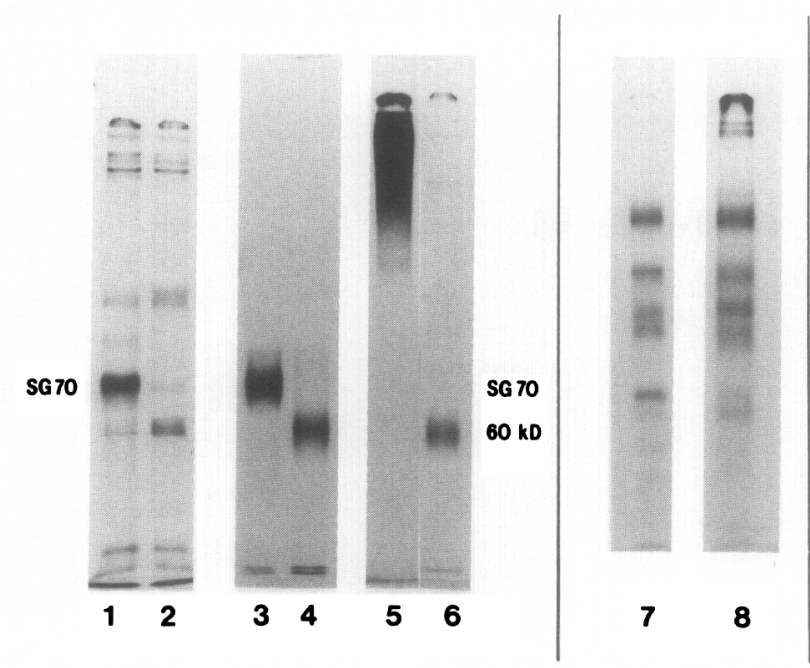

FIG. 4. SG 70 is a short-lived precursor of extracellular matrix material. 1, $40 \mathrm{~min}$ after application of pheromone, Volvox spheroids were pulse labeled $\left(30 \mathrm{~min}\right.$ ) with ${ }^{85} \mathrm{SO}_{4}^{2-}$. The SDS extract from 25 spheroids was applied to a $8 \%$ SDS-polyacrylamide gel. 2, Volvox spheroids were pulse labeled as in 1, followed by a chase for a period of $90 \mathrm{~min}$. 3, Reelectrophoresis of isolated ${ }^{35} \mathrm{~S}$-labeled SG 70 (Materials and Methods). 4, Isolated ${ }^{95} \mathrm{~S}$-labeled SG 70 after treatment with anhydrous hydrogen fluoride (Materials and Methods). 5, Pulse-chase-labeled Volvox spheroids were exhaustively extracted with hot $3 \%$ SDS (Materials and Methods) and the remaining Volvox "ghosts" disrupted by ultrasonic treatment. The ultrasonic lysate was then applied to a SDSpolyacrylamide gel ( $8 \%$ ). 6 , Lysate prepared as in 5 , but subsequently treated with anhydrous hydrogen fluoride. 7 and 8 , The samples from lanes 4 and 6, after treatment with $\mathrm{CNBr}$ (Materials and Methods) and reelectrophoresis on a $15 \%$ polyacrylamide gel. Labeled material was visualized by fluorography.

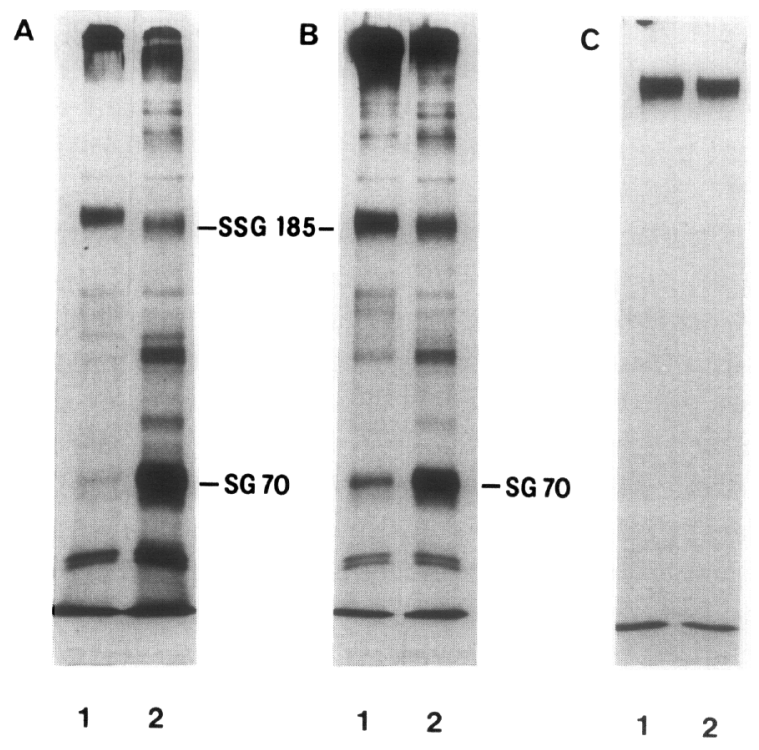

FIG. 5. SG 70 is synthesized by somatic cells. Fluorograms of SDSpolyacrylamide gels $(8 \%)$ loaded with extracts from cells pulse labeled (30 min) with ${ }^{35} \mathrm{SO}_{4}^{2-}$ in the absence (1) or presence (2) of pheromone $(0.1 \mathrm{p} M)$. Somatic cell sheets and gonidia were isolated after release from mother colonies (Materials and Methods). $30 \mathrm{~min}$ after the addition of pheromone the samples were pulse labeled with ${ }^{35} \mathrm{SO}_{4}^{2-}$ and thereafter they were boiled for $10 \mathrm{~min}$ in SDS sample buffer. The extracts were submitted to electrophoresis. The corresponding fuorography shows the extracts obtained from: (A) intact spheroids, (B) somatic cell sheets, and (C) isolated gonidia.

solubilizes most intracellular components but leaves intact the insoluble extracellular matrix structure (Kirk and Kirk, 1983). Thus colorless Volvox "ghosts" are obtained. Treatment of these "ghosts" with anhydrous HF $\left(0^{\circ} \mathrm{C}, 90 \mathrm{~min}\right)$ and subsequent analysis by SDS-polyacrylamide gel electrophoresis yields a single labeled degradation product which comigrates with the HF degradation product of SG 70 (Fig. 4, lanes 4 and 6). Identity of both degradation products was proven after $\mathrm{CNBr}$ cleavage (Gross and Witkop, 1961) followed by comparison of the resulting peptide patterns by SDS gel electrophoresis (Fig. 4, lanes 7 and 8). Thus SG 70 is a precursor protein for the insoluble extracellular matrix. The monomeric SG 70 appears to be localized extracellularly by itself because it can be extracted quantitatively from intact Volvox colonies by extremely mild conditions ( $0.3 \mathrm{M} \mathrm{NaCl}, 20 \mathrm{~min}$ at room temperature). These conditions do not cause any liberation of cytoplasmic proteins.

\section{SG 70 is Synthesized by Somatic Cells}

Volvox spheroids easily dissociate into somatic cell sheets and free gonidia upon mild mechanical stress, as 
exerted by forcing them through a drawn pipette. $\mathrm{Pu}$ rified somatic cell sheets and suspensions of pure gonidia (see Materials and Methods) were incubated with the sexual pheromone and $30 \mathrm{~min}$ later pulse labeled with ${ }^{35} \mathrm{SO}_{4}^{2-}$. SG 70 synthesis took place exclusively within the somatic cell sheets (Fig. 5B). Pulse labeling of the gonidial suspensions did not reveal any SG 70 synthesis by these cells, although a 20 -fold amount of gonidia relative to intact colonies was applied to SDS-polyacrylamide gel electrophoresis (Fig. 5C). This lack of SG 70 biosynthesis by gonidia was found at the time of dissociation as well as after several hours of cultivation (until the initiation of cleavages). Somatic cells, however, isolated from Volvox spheroids at different developmental stages, responded in essentially the same manner, regardless the stage investigated. No qualitative difference was found between somatic cells from Volvox spheroids 10 or $2 \mathrm{hr}$ before the onset of gonidial cleavages. Even somatic cells from spheroids containing cleaving embryos still responded to the pheromone with the production of SG 70 and F-SG.

Remarkably, this is also true for intact Volvox spheroids. Even at the developmental stage of gonidial cleavages, by which time the pheromone is completely inef- fectual in eliciting sexual development, the inducibility of SG 70 synthesis remains unaffected.

\section{SG 70 is a Tyrosine Sulfate-Containing Glycoprotein}

${ }^{35} \mathrm{~S}$ radioactivity incorporated into SSG 185 or F-SG during a pulse-labeling experiment lasting less than 30 min is quantitatively recovered as inorganic sulfate after mild acid hydrolysis, indicating the presence exclusively of $O$-sulfate ester linkages (identified as sugar sulfates). Reductive assimilation of sulfate and, as a consequence, labeling of sulfur-containing amino acids seems therefore of minor importance within this time scale. Accordingly, only very few radioactive bands become detectable in SDS-polyacrylamide gel patterns obtained from pulse-labeled Volvox lysates. It was therefore highly unexpected that this did not hold for SG 70 synthesis as well. In SG 70 only $20 \%$ of the total incorporated ${ }^{35} \mathrm{SO}_{4}^{2-}$ radioactivity was recovered as sulfate upon mild acid hydrolysis.

To characterize the chemical nature of ${ }^{35} \mathrm{~S}$ radioactivity incorporated, SG 70 after peroxidation was hydrolyzed by $6 \mathrm{~N} \mathrm{HCl}$ for $17 \mathrm{hr}$ at $105^{\circ} \mathrm{C}$ (Hirs, 1967a). The resulting radioactive products were separated by thin layer chromatography (Fig. 6A). About $50 \%$ of incor-

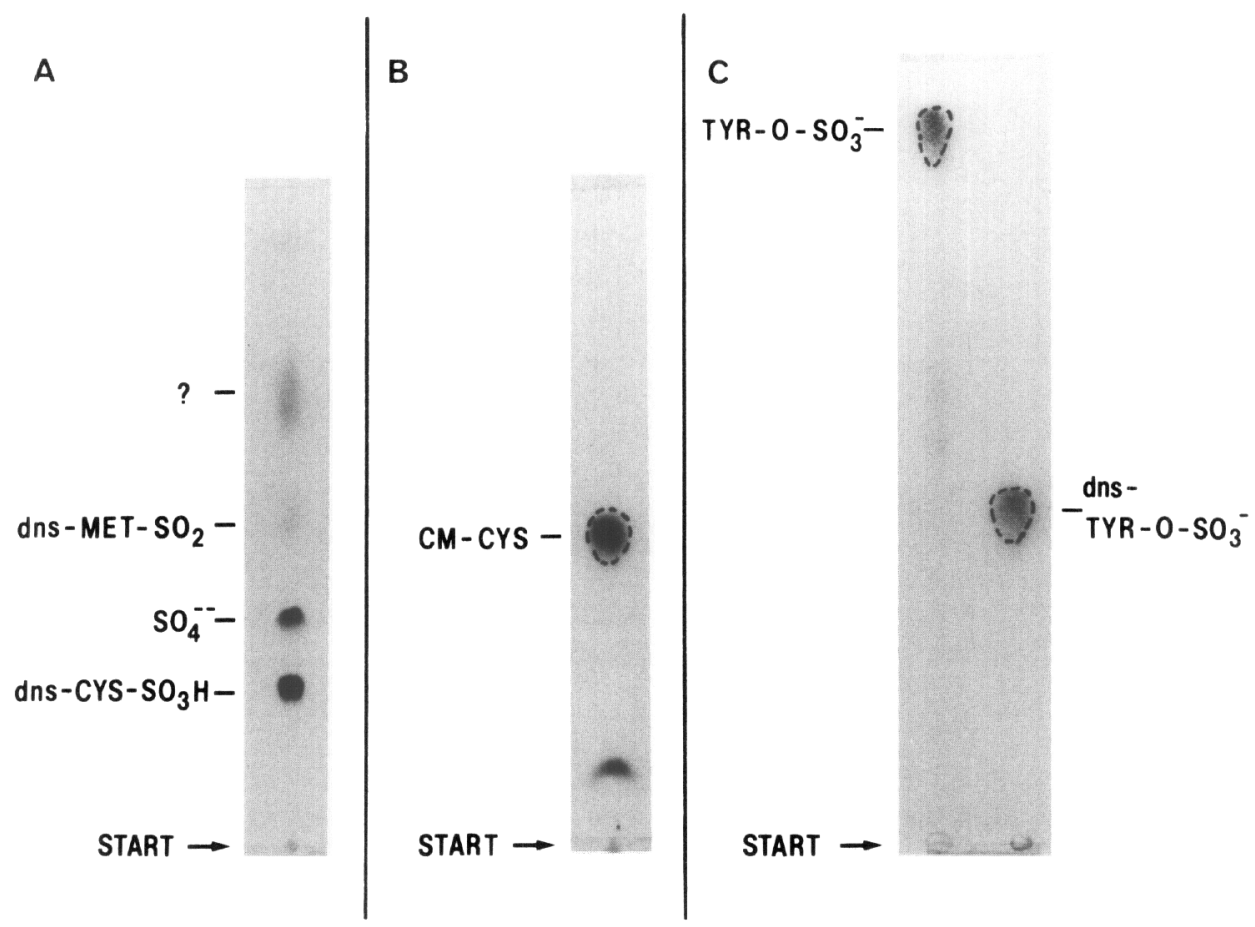

FIG. 6. Fluorograms of thin layer chromatograms of ${ }^{85}$ S-labeled SG 70 hydrolysates. (A) ${ }^{85}$ S-labeled SG 70 was peroxidized with HCOOH/ $\mathrm{H}_{2} \mathrm{O}_{2}$, hydrolyzed, and dansylated as described under Materials and Methods. Labeled products were separated by thin layer chromatography on polyethylene imine cellulose with $0.3 \mathrm{M} \mathrm{NH}_{4} \mathrm{HCO}_{3}$ as solvent. The positions of the internal standards are indicated. (B) ${ }^{35} \mathrm{~S}-\mathrm{labeled} \mathrm{SG} 70$ was carboxymethylated and hydrolyzed as described under Materials and Methods. The radioactive products were separated by high-voltage thin-layer electrophoresis. The position of the internal standard is indicated, detected by ninhydrin staining. (C) ${ }^{36} \mathrm{~S}$-labeled SG 70 was hydrolyzed with $0.2 \mathrm{M} \mathrm{Ba}(\mathrm{OH})_{2}$ as described under Materials and Methods. Labeled products were analyzed by high-voltage thin-layer electrophoresis before, (lane 1) and after dansylation (lane 2). Dashed lines indicate the positions of tyrosine- $O$-sulfate and dansyltyrosine- $O$-sulfate standards. 
porated radioactivity comigrated with authentic cysteic acid, a further $20 \%$ were recovered as inorganic sulfate, and about $20 \%$ as a yet unidentified compound. Less than $5 \%$ of radioactivity were found to be incorporated into methionine. The presence of radioactive cysteine in SG 70 was also demonstrated by carboxymethylation of SG 70 (White, 1967; Hirs, 1967b) followed by hydrolysis and product analysis by high-voltage thin-layer electrophoresis (Fig. 6B). Again, about 50\% of the total radioactivity incorporated comigrated with authentic $S$-carboxymethylcysteine. Thus, cysteine residues of the SG 70 polypeptide become labeled, although the distinct pulse-labeling patterns (Fig. 2) indicate that ${ }^{35} \mathrm{~S}$ labeling of intracellular proteins is of minor importance during that time. This unexpected finding could easily be explained in terms of different rates of polypeptide synthesis, i.e., SG 70 production greatly exceeding that of other proteins. Indeed preliminary $\left[{ }^{14} \mathrm{C}\right]$ arginine pulselabeling experiments support this interpretation.

Since tyrosine sulfate was recently detected in a $\mathrm{Vol}$ vox protein from sperm cells (Huttner, Wenzl, and Sumper, unpublished data), SG 70 was also checked for the occurrence of this modification. ${ }^{35} \mathrm{~S}-L a b e l e d ~ S G ~ 70$ was hydrolyzed with $\mathrm{Ba}(\mathrm{OH})_{2}$ (Bettelheim, 1954; Lee and Huttner, 1983) and the resulting products were freed of underivatized amino acids by passage through a column of Dowex 50 in the $\mathrm{H}^{+}$form. The eluting radioactive substance was shown to be identical with synthetic tyrosine- $O$-sulfate by high-voltage thin-layer electrophoresis as well as by derivatization with dansyl chloride and subsequent high-voltage electrophoresis (Fig. 6C).

Tyrosine sulfate accounts for $10 \%$ of the total radioactivity incorporated into SG 70 . Treatment of ${ }^{35} \mathrm{~S}-\mathrm{la}-$ beled SG 70 with anhydrous HF (Mort and Lamport (1977), a procedure which selectively splits $O$-glycosidic bonds) results in the lowering of its apparent molecular weight to a value of about $60 \mathrm{kDa}$ (Fig. 4, lanes 3 and 4). This observation indicates the presence of proteinbound saccharides in SG 70. This conclusion is supported by preliminary ${ }^{14} \mathrm{CO}_{2}$ incorporation experiments, in which mainly $\left[{ }^{14} \mathrm{C}\right]$ mannose could be detected in SG 70 by radio gas chromatography (Holst and Sumper, unpublished results). Therefore, the remaining $10 \%$ of radioactivity incorporated as $O$-sulfate esters is most probably bound as sugar sulfate, as is the case with the SSG 185 and F-SG molecules.

Taken together these data characterize SG 70 as a sulfated glycoprotein which in addition contains sulfate bound to tyrosine residues.

\section{The Pheromone Itself Triggers the Gonidium}

The biochemical mechanism of sexual induction in Volvox remains essentially an unsolved problem. The first physical interaction between Volvox spheroids and the pheromone has to occur at the surface of the colony, which is entirely surrounded by extracellular matrix material. Subsequently, the pheromone's message has to reach the target cell-the gonidium-which is well shielded from the environment (Fig. 1). This could be effected either by direct transport of the pheromone itself to the cell membrane of the gonidium, or by a signal transforming system within the extracellular matrix that translates the pheromone's message by production of a second messenger molecule. In this respect, it is of considerable interest whether isolated gonidia still respond to the sexual pheromone and develop sexual individuals. It has repeatedly been stated in the literature (Gilles et al., 1984; Jaenicke, 1979) that this is not the case, without, however, any presentation of experimental conditions. We therefore reinvestigated the pheromone's action on gonidia in isolation under a number of different experimental conditions. Nearly $100 \%$ of the gonidial population responded to the pheromone and developed to sexual individuals (Fig. 7) when cultivated on solid media (preferably starch or agarose gels with a low content of sulfated polysaccharides, which might bind the positively charged pheromone). A lower percentage of the gonidial population (about 50-60\%) responded to the pheromone if cultivation was performed in suspension using culture petri dishes. No or a very low response was observed if cultivation was performed in test tubes filled to two-thirds with medium, standard conditions for propagation of intact Volvox spheroids. Thus, efficient aeration of isolated gonidia appears to be essential for successful induction of isolated gonidia. Preparations of isolated gonidia (see Materials and Methods) are completely free of sulfated glycoproteins such as SSG

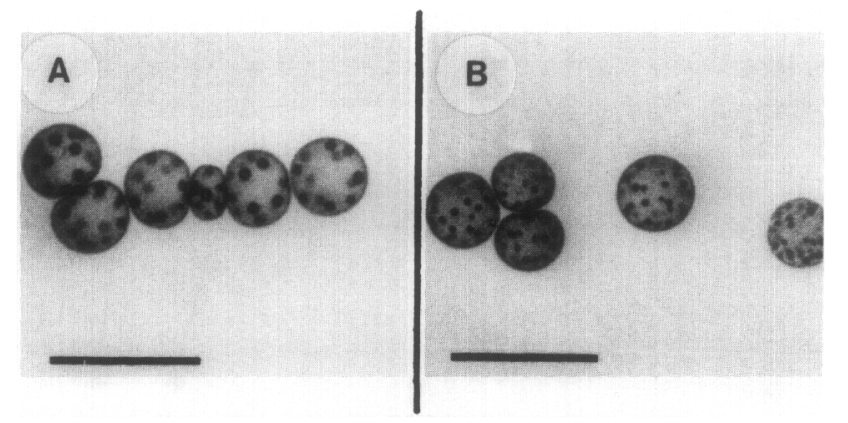

FIG. 7. Sexual inducibility of isolated free gonidia. Synchronously growing Volvox spheroids (female strain HK 10) were dissociated into somatic cell sheets and free gonidia $12 \mathrm{hr}$ before the initiation of embryonic cleavages. Purified gonidia (Materials and Methods) were plated on $6.5 \%$ starch gels containing Volvox medium. (A) Control (asexual development in the absence of pheromone); (B) development of gonidia in the presence of sexual pheromone $(1 \mathrm{p} M)$. All free gonidia developed into egg-bearing spheroids. Photographs were taken $10 \mathrm{hr}$ after the end of embryogenesis. Bar, $1.0 \mathrm{~mm}$. 
185 or SSG 140, which are located in the extracellular matrix and synthesized exclusively by somatic cells (Kirk and Kirk, 1983; Wenzl et al., 1984). Since these glycoproteins can easily be radiolabeled even with carrier-free ${ }^{35} \mathrm{SO}_{4}^{2}$, their detection can be used as a sensitive probe for extracellular matrix material. Nonetheless, to exclude the possibility that traces of matrix material remain attached to isolated gonidia that could play a functional role (e.g., signal transduction) in the process of sexual induction, we repeated the induction experiments with gonidia under much more stringent conditions. After their isolation, gonidia were treated either with pronase $(100 \mu \mathrm{g} / \mathrm{ml})$ or with subtilisin $(100 \mu \mathrm{g} / \mathrm{ml})$ for $60 \mathrm{~min}$ at $30^{\circ} \mathrm{C}$. This treatment should degrade any remaining extracellular matrix material. After this treatment, gonidia were washed to remove the protease and then incubated in the presence of sexual pheromone. Even after this harsh treatment more than $30 \%$ of the gonidial population still responded to the sexual pheromone. From this result, we must conclude, that it is the pheromone itself that triggers the gonidium, rather than a second messenger molecule produced within the extracellular matrix.

A serial pheromone dilution experiment was performed to compare the sensitivity of intact Volvox spheroids and isolated free gonidia to the pheromone. The results of these experiments are summarized in Fig.

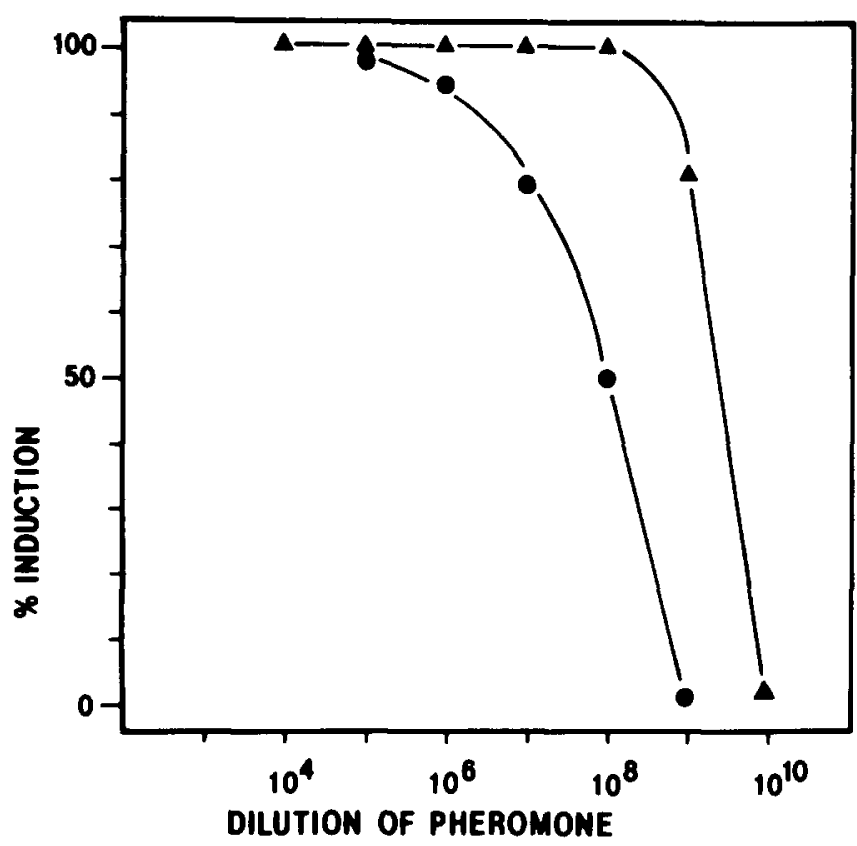

FIG. 8. Dose dependency of sexual induction by the pheromone. Intact Volvox spheroids $(\Delta)$ or isolated free gonidia ( ) were plated on $6.5 \%$ starch gels containing pheromone (Materials and Methods). For each dilution of pheromone, at least 100 gonidia were plated out. The percentage of sexual induction was determined $12 \mathrm{hr}$ after the end of embryogenesis by stereomicroscopic examination.
8. Isolated gonidia respond with a reduced sensitivity, the response being elicited by a pheromone concentration 1-2 orders of magnitude higher than that required to trigger sexual development of intact Volvox spheroids. This reduced sensitivity of isolated gonidia suggests that an amplification mechanism operates within the intact Volvox spheroid, raising the effective pheromone concentration 50- to 100 -fold at the surface of the gonidium.

\section{DISCUSSION}

All early biochemical responses to the pheromone detected so far are localized within the extracellular matrix. The extracellular sulfated glycoproteins described in this paper are synthesized by the somatic cells rather than by the gonidia, the ultimate recipients of the pheromone's message. This synthetic capacity of the somatic cell responds to the pheromone with the same extreme sensitivity as does the process of induction of sexual development. The somatic cells respond even in the absence of reproductive cells. These facts make a role for the somatic cell and its surrounding extracellular matrix likely in the process of sexual induction.

What could be the function of the pheromone-induced sulfated glycoproteins? Three alternatives should be considered:

(1) The sulfated glycoproteins are members of a signal-transducing system that translates (and amplifies) the pheromone's message. If so, a second messenger produced by the somatic cell would trigger the gonidium rather than the pheromone by itself.

(2) The sulfated glycoproteins are part of an amplification and (or) transport system, which collects and (or) transports the positively charged pheromone through the extracellular matrix to the gonidial cell surface.

(3) The sulfated glycoproteins are not involved in the mechanism of induction at all, but are synthesized as a consequence of sexual induction, preparing the extracellular matrix for the mating process (e.g., production of a sperm-binding receptor in female strains).

The third possibility is highly unlikely because the newly synthesized sulfated glycoproteins are localized within the extracellular matrix of the mother spheroid rather than within the developing embryo. Since, however, it is only the extracellular matrix of the following generation that is involved in the mating process (e.g., has to bind sperm cells), the modification of the mother's matrix for that purpose would make no sense.

A mechanism for induction corresponding to possibility 1 was proposed recently (Gilles et al., 1984; Gilles et al., 1985). These authors demonstrated that binding 
sites for the pheromone exist in the extracellular matrix allowing a significant accumulation of pheromone within Volvox spheroids. Bound pheromone was then proposed to activate a cascade-like signal transforming system, which ultimately results in a lowering of extracellular levels of cyclic nucleotides. These extracellular second messengers should then trigger the gonidium for sexual development. This model predicts that isolated free gonidia will not respond to the pheromone because they lack the essential signal transducing system provided by the extracellular matrix. It has repeatedly been reported in the literature (e.g., Gilles et al., 1984) that gonidia in isolation indeed will not respond to the pheromone, even though they remain healthy and capable of normal asexual development. In our hands, however, up to $100 \%$ of a population of isolated gonidia reproducibly initiated sexual development in the presence of pheromone. Thus, it appears more likely that the pheromone by itself triggers the gonidium, rather than a second messenger produced within the extracellular matrix. However, the sensitivity of isolated gonidia to the pheromone turned out to be lowered by nearly two orders of magnitude. We therefore suggest that the role of pheromone-induced glycoproteins is to collect the positively charged pheromone molecules and to direct the pheromone's transport through the highly negatively charged extracellular matrix to the gonidia's cell membrane. Since SG 70 was characterized as a precursor molecule for an insoluble structural element of the extracellular matrix one could think of the possibility that this structure is part of a pore-like pheromone transport system. We are currently engaged in raising monoclonal antibodies against SG 70 in order to localize this protein by immunofluorescence microscopy. If SG 70 antibodies able to interfere with the process of sexual induction become available, the suggested role of this sulfated glycoprotein as a pheromone "carrier" could effectively be tested: this suggestion being correct, such an antibody should only inhibit sexual induction in intact Volvox spheroids but should leave unaffected sexual ind 1 , tion of isolated gonidia.

Pheromone-induced synthesis of SG 70 and F-SG does also occur in Volvox spheroids at developmental stages at which the pheromone is wholly ineffectual in eliciting sexual development (e.g., at the time of early gonidial cleavages). This fact further strengthens the hypothesis that the observed changes within the extracellular matrix do not constitute the central part of the trigger mechanism.

\footnotetext{
We thank Brigitte Seidel for expert technical assistance. The assistance with the English by Dr. Peter Orlean is gratefully acknowledged. This work has been supported by the Deutsche Forschungsgemeinschaft (SFB 43).
}

\section{REFERENCES}

BETTELHEim, F. R. (1954). Tyrosine-O-sulfate in a peptide from fibrinogen. J. Am. Chem. Soc. 76, 2838-2839.

BONNER, W. M., and LASKEY, R. A. (1974). A film detection method for tritium labeled proteins and nucleic acids in polyacrylamide gels. Eur. J. Biochem. 46, 83-88.

GILles, R., BitTNER, C., and JAENicke, L. (1981). Site and time of formation of the sex-inducing glycoprotein in Volvox carteri. FEBS Lett. 124, 57-61.

GILLES, R., and JAENICKE, L. (1982). Differentiation in Volvox carteri: Study of pattern variation of reproductive cells. $Z$. Naturforsch. $C$ 37, 1023-1030.

GILlES, R., GiLles, C., and JAENICKE, L. (1983). Sexual differentiation of the green alga Volvox carteri: Involvement of extracellular phosphorylated proteins. Naturwissenschaften 70, 571-572.

Gilles, R., Gilles, C., and JAENiCKe, L. (1984). Pheromone-binding and matrix-mediated events in sexual induction of Volvox carteri. Z. Naturforsch. C 39, 584-592.

Gilles, R., MoKa, R., Gilles, C., and JAenicke, L. (1985). Cyclic AMP as an intraspheroidal differentiation signal in Volvox carteri. FEBS Lett. 184, 309-312.

GREEN, K. J., and KIRK, D. L. (1981). Cleavage patterns, cell lineages, and development of a cytoplasmatic bridge system in Volvox embryos. J. Cell Biol. 91, 743-755.

GREEN, K. J., and KIRK, D. L. (1982). A revision of the cell lineages recently reported for Volvox carteri embryos. J. Cell Biol. 94, 741742.

Gross, E., and WiTKop, B. (1961). Selective cleavage of the methionyl peptide bonds in ribonuclease with cyanogen bromide. J. Am. Chem. Soc. 83, 1510-1511.

HIRS, C. H. W. (1967a). Determination of cystine as cysteic acid. In "Methods in Enzymology" (C. H. W. Hirs, ed.), Vol. 11, pp. 59-62. Academic Press, New York.

HIRs, C. H. W. (1967b). Reduction and S-carboxymethylation of proteins. In "Methods in Enzymology" (C. H. W. Hirs, ed.), Vol. 11, pp. 199-203. Academic Press, New York.

JAENICKE, L. (1979). Induction of sexuality in Volvox carteri f. nagariensis: A variation on the theme "Receptor/Ligand Interactions". In "Molecular Mechanisms of Biological Recognition" (B. Balaban, ed.), pp. 413-418. Elsevier/North-Holland Biomedical Press, New York.

Janet, C. (1923). "Le Volvox. Troisieme Memorie." Protat Freres, Macon.

KIRK, D. L., and KIRK, M. M. (1983). Protein synthetic patterns during the asexual life cycle of Volvox carteri. Dev. Biol. 96, 493-506.

KOCHERT, G. (1968). Differentiation of reproductive cells in Volvox carteri. J. Protozool. 15, 438-452.

KOCHERT, G., and OLSON, L. W. (1970). Ultrastructure of Volvox carteri: The asexual colony. Arch. Mikrobiol. 74, 19-30.

LAEMMLI, U. K. (1970). Cleavage of structural proteins during the assembly of the head of the bacteriophage T 4 . Nature (Lomdon) 227, 680-685.

LEE, R. W. H., and HuTrNER, W. B. (1983). Tyrosine-O-sulfated proteins of PC 12 pheochromocytoma cells and their sulfation by a tyrosylprotein sulfotransferase. J. Biol. Chem. 258, 11326-11334.

MoRT, A. J., and LAMPORT, D. T. A. (1977). Anhydrous hydrogen fluoride deglycosylates glycoproteins. Anal. Biochem. 82, 289-309.

Powers, J. H. (1908). Further studies in Volvox with descriptions of three new species. Trans. Am. Microsc. Soc. 28, 141-175.

Provasoli, L., and PintNer, I. J. (1959). Artificial media for freshwater algae: Problems and suggestions. In "The Ecology of Algae" (Tyron, C. A. and Hartman, R. T., eds.), Special Publication No. 2, "Pymatuning Laboratory of Field Biology," pp. 84-96. University of Pittsburgh. 
SEILER, N. (1970). Use of the dansyl reaction in biochemical analysis. In "Methods of Biochemical Analysis" (D. Glick, ed.), Vol. 18, pp. 259-337. Interscience, New York.

STARR, R. C. (1969). Structure, reproduction, and differentiation in Volvox carterif. nagariensis Iyengar, strains HK9 \& 10. Arch. Pro tistenk. 111, 204-222.

StaRR, R. C. (1970). Control of differentiation in Volvox. Dev. Biol Suppl. 4, 59-100.

STARR, R. C., and JAENICKE, L. (1974). Purification and characterization of the hormone initiating sexual morphogenesis in Volvox carterif. nagariensis Iyengar. Proc. Natl. Acad. Sci. USA 71, 1050-1054.

SUMPER, M. (1979). Control of differentiation in Volvox carteri. A model explaining pattern formation during embryogenesis. FEBS Lett. 107, 241-246.

Tallan, H. H., Bella, S. T., STein, W. H., and Moore, S. (1955). Tyrosine-O-sulfate as a constituent of normal human urine. J. Biol. Chem. 217, 703-708.
WENZL, S., and SUMPER, M. (1981). Sulfation of a cell surface glycoprotein correlates with the developmental program during embryogenesis of Volvox carteri. Proc. Natl. Acad. Sci. USA 78, 3716-3720.

WENZL, S., and SUMPER, M. (1982). The occurrence of different sulphated cell surface glycoproteins correlates with defined developmental events in Volvox. FEBS Lett. 143, 311-315.

WENZL, S., ThYM, D., and SuMPER, M. (1984). Development-dependent modification of the extracellular matrix by a sulphated glycoprotein in Volvox carteri. EMBO J. 3, 739-744.

WhITE, F. H. (1967). Reduction and reoxidation at disulfide bonds. In "Methods in Enzymology" (C. H. W. Hirs, ed.), Vol. 11, pp. 481-484. Academic Press, New York.

Wifi.and, F., Heitzer, R., and Schaffer, W. (1983). Asparaginylglucose: Novel type of carbohydrate linkage. Proc. Natl. Acad. Sci. USA 80, 5470-5474. 